\title{
Ağır Metal Analizlerinde Kullanılan Bazı Karayosunu Türlerinin Demir Absorplama Yetenekleri
}

\author{
Bahadır Koz \\ Giresun Üniversitesi, Matematik ve Fen Bilimleri Eğitimi Bölümü, 28049, Giresun, Türkiye
}

Geliş Tarihi: 16.10 .2018

Sorumlu Yazar: bahadır.koz@giresun.edu.tr

Kabul Tarihi: 29.11.2018

\section{$\ddot{\mathbf{O} z}$}

Karayosunlarının bütün dünyada 23000 türü vardır ve ağır metal kirlilik çalışmalarında indikator olarak çok fazla kullanılmaktadır. Bu çalışmada, biz EDXRF spekrometre yöntemini kullanarak altı farklı karayosunu türünün demir absorplama kapasitesini ilk kez analiz ettik. 400 mesh'lik eleklerden elenerek $40 \mathrm{mg}$ 'llk tablet haline getirilen karayosunu örnekleri ${ }^{241} \mathrm{Am}$ radyoaktif kaynağından yayılan $59,5 \mathrm{keV}$ 'lik fotonlara maruz bırakıldı. Numunelerden geçen fotonlar Ultra LEGe dedektörü ve buna bağlı çok kanallı analizör kullanılarak sayıldı. Altı farklı karayosunu türünün absorplama kapasiteleri, sırasıyla şu ş̧ekilde azaldığı bulunmuştur; Eurhynchium striatum, Hypnum cupressiforme, Pleurozium schreberi, Eurhynchium striatulum, Homalothecium sericeum ve Thuidium tamariscinum. Daha sonra, Türkiye'nin önemli sahil otoyollarında biri olan, Sarp-Samsun otoyolu boyunca farklı bölgelerden elde edilmiş karayosunu türleri için belirlenen Fe absorpsiyon seviyelerindeki muhtemel değişimlerle düzenledik.

Anahtar Kelimeler: Karayosunu, Demir, Absorpsiyon, EDXRF

\section{Iron adsorption capacity of some moss species used for heavy metal analysis}

\begin{abstract}
Mosses, covering about 23000 species of all land plants in the world, have been widely used as an indicator of heavy metal pollution in many studies. In this study, we have first analyzed the Iron adsorption capacities of six different moss species by means of using EDXRF spectrometry method. For analysis with EDXRF, the $40 \mathrm{mg}$ tablets which were prepared from lichen and moss samples by sieving with 400 mesh, were irradiated by ${ }^{241} \mathrm{Am}$ radioactive sources emitting $59,5 \mathrm{keV}$ photons. Photons passed through the samples were counted by Ultra LEGe detector with multi channel analyser. The adsorption capacities of the studied six mosses are found in descending order as Eurhynchium striatum, Hypnum cupressiforme, Pleurozium schreberi, Eurhynchium striatulum, Homalothecium sericeum and Thuidium tamariscinum. Then, we have regularized the Fe adsorption levels for the moss species obtained from different regions along one of the important coast highway in Turkey, namely Sarp-Samsun highway, with respect to the determined adsorption capacities.
\end{abstract}

Key words: Moss, Iron, Adsorption, EDXRF 


\section{Giriş}

Son yıllarda meydana gelen şehirleşme ve sanayideki artıştan dolayı, birçok ülkede karasal çevre üzerinde ciddi çevre bozulmaları meydana geldi. Şehir havasındaki ağır metallerin monitörlenmesi, dünyanın bir çok yerindeki çevre planlamarının ve kontrol programlarının esasını oluşturdu. Biyomonitörleme; Biyosferin özellikleri hakkındaki bilginin elde edilmesi amacıyla biyomateryallerin veya canlı organizmaların kullanılma tekniğidir (Wolterbeek, 2002). Karayosunları, atmosferik kirliliğin biyomonitörlenmesi amacıyla en uygun canlı organizmalardan birisidir. Karayosunlarının, yüksek bitkilerde bulunan gibi kökleri ve kütiküla tabakası bulunmaz, bu yüzden de mineral emilimini bütün yüzeyleri ile yaparlar. Lee ve ark. (2005)'na göre karayosunları, havadaki iz elementlerin ve ağır metallerin belirlenmesinde mükemmel biyomonitör bitkilerdir. Onların dokularında, bu ağır metaller büyük oranlarda birikirler. (Grodzinska ve Szarek-Lukaszewska, 2001; Uyar ve ark., 2007)

İndikatör bitkiler olarak kullanılan karayosunları birkaç avantaja sahiptirler: 1. Azı karayosunları, endüstriyel bölgelerde ve şehirlerin çevrelerinde doğal olarak bulunabilir 2. Onlar epidermis ya da kütikülaları sahip değildirler, bu yüzden metal iyonlarını bütün yüzeyleriyle emerler 3. Karayosunlarında, yüksek bitkiler olduğu gibi kök gövde yaprak farklılaşması görülmez, bu yüzden de havadaki her şeyi emerler 4. İletim demetleri olmadığından dolayı mineral taşınması zayıftır 5. Karayosunları metalleri pasif olarak biriktirirler 6. Karayosunları, atmosferik birikim miktarının bir fonksiyonu olarak, çoğu metallerin yoğunluklarını gösterirler (Grodzinska ve Szarek-Lukaszewska, 2001)

Demir yeryüzünde çok bulunur fakat bununla birlikte de araçların motor ve kaporta gibi bölümlerinde de kullanılmaktadır, dolayısıyla trafikle ilişkili ağır metallerden birisidir. Çevre korumasına az bütçe ayıran bazı ülkeler için demir emisyonlarının monitörlenmesi, üzerinde önemle durulması gereken bir konudur (Harrison ve ark., 1996; Kristensson ve ark., 2004; Zechmeister ve ark., 2005).

$\mathrm{Bu}$ çalışmada, biz EDXRF (Enerji Ayırımlı X-Işınları Floresans Spektrometresi) spektrometresi kullanarak, çevre kirliliğinin biyomonitörlenmesinde kullanılan altı farklı karayosunu türünün demir biriktirme kapasitelerini ilk kez inceledik. Daha sonra, Sarp-Samsun sahil karayolu (Koz ve ark., 2008) çevresindeki karayosunlarının analiz edilmesi sonucu elde edilen demir konsantrasyonları ile bu çalışmadan elde ettiğimiz sonuçları değerlendirerek, bu karayolu çevresindeki demir konsantrasyonlarının muhtemel değişiminin kıyaslamasını yaptık.

Bu çalışmada kullanılan altı karayosunu türü Pleurokarp (Halı şeklinde olan karayosunları) türlerden seçilmiştir, bu Pleurokarp türler analiz çalışmalarında çok kullanılan ve Akrokarp türlerden daha geniş bir yaprak yüzeyine sahiplerdir; Homalothecium sericeum, Thuidium 
tamariscinum, Eurhyncnium striatulum, Eurhyncnium striatum, Hypnum cupressiforme ve Pleurozium schreberi' dir. Karayosunu numuneleri insan kaynaklı çevre kirliliğinden uzak olan Giresun ili Kümbet yaylasından 2006 yılında toplanmıştır. Elde edilen sonuçlar; Koz ve ark., (2008) tarafından yapılan Sarp-Samsun makalesinden elde edilmiş demir konsantrasyon değerleri üzerinde normalizasyon yapılarak gösterilmiştir nasıl bir değişim olabileceği. Böyle bir analizle ve normalizasyon işlemiyle bizim amacımız; altı farklı karayosununun absorpsiyon kapasitelerini belirlemek ve anatomik ve morfolojik farklılıklarının bu kapasiteyle ilişkilerini ortaya koymaktır. İkinci amacımız ise; Çevre kirliliğinin ortaya konulması için yapılan bu tür analiz çalışmalarındaki muhtemel değişimleri belirlemektir.

\section{Materyal ve Metot}

\section{Örneklerin Toplanması, Hazırlanması ve Demir absorpsiyon deneyi}

$\mathrm{Bu}$ araştırmada kullanılan karayosunu örnekleri, insan kaynaklı kirlilikten uzak olan Giresun ili Kümbet yaylasından toplanmıştır. Karayosunlarının tür teşhisi, Introduction to Bryology (Schofield, 2001), Die Moos-und Farnpflanzen Europas (Frey ve ark., 1995), The Moss Flora of Britain and Ireland (Smith, 2004) and Flora Dei Muschi D'Italia (Pedrotti, 2001) gibi flora kitaplarından yararlanılarak gerçekleştirildi. Bu altı karayosununun (Homalothecium sericeum (Hedw.) B.S.G., Thuidium tamariscinum (Hedw.) B.S.G., Eurhyncnium striatulum (Spruce) B.S.G., Eurhyncnium striatum (Hedw.) Schimp., Hypnum cupressiforme Hedw., Pleurozium schreberi (Brid.) Mitt), Fe absorplama yeteneklerini kıyaslayabilmek için $25 \times 36 \times 55 \mathrm{~cm}^{3}$ ebatındaki kutulara yerleştirildi. Bu karayosunları; bizim çalışmalarımızda sıklıkla kullandığımız ve arazide de bol bulunan türlerdir. Bu altı tür dört gruba bölündü. Birinci gruba hiç demir çözeltisi verilmedi. İkinci gruba 0.005 \% Fe'lik demir çözeltisi, Üçüncü gruba $0.05 \%$ Fe'lik demir çözeltisi ve dördüncü gruba 0.5 \% Fe'lik demir çözeltisi verildi. Hazırlanan çözeltiler Atomizer denilen aletle, her seferinde $100 \mathrm{ml}$ olmak üzere, 10 gün boyunca ve her 24 saatte bir tekrarlanarak numunelere püskürtüldü. Üç farklı çözelti aşağıdaki şekilde hazırlandı.

$$
\begin{array}{ll}
\text { 1. } & 0.5 \% \mathrm{Fe} \text { çözeltisi } \rightarrow 7.85 \mathrm{~g} \mathrm{Fe}\left(\mathrm{CH}_{3} \mathrm{COO}\right)_{2}+1 \mathrm{~L} \text { saf su } \\
\text { 2. } & 0.05 \% \mathrm{Fe} \text { çözeltisi } \rightarrow 100 \mathrm{ml} 0.5 \% \mathrm{Fe}\left(\mathrm{CH}_{3} \mathrm{COO}\right)_{2}+1 L \text { saf su } \\
\text { 3. } & 0.005 \% \mathrm{Fe} \text { çözeltisi } \rightarrow 100 \mathrm{ml} 0.05 \% \mathrm{Fe}\left(\mathrm{CH}_{3} \mathrm{COO}\right)_{2}+1 L \text { saf su }
\end{array}
$$

Daha sonra numuneler kutulardan alındı ve $100{ }^{\circ} \mathrm{C}$ 'de 20 saat İnkubatör'de kurutuldu. Kurutulan örnekler Spex değirmeninde öğütüldü. Toz haline getirilen numuneler parçacık büyüklüğü etkisini ihmal etmek için 400 Mesh'lik elekte elendi, $38 \mu \mathrm{m}$ çapında parçacıklar oluştu. Toz haline getirilen numuneler $10^{-4}$ hassasiyete sahip Sartorios Bp 110s terazisi yardımıla $40 \mathrm{mg}$ 
tartıldı ve press yardımıyla basınç uygulanarak $13 \mathrm{~mm}$ çapında tabletler oluşturuldu. Oluşturulan tabletler EDXRF (Enerji Ayrımlı X Işını Floresans Spektrometresi)'de sayıma hazır hale getirildi. Tablet haline getirilen numuneler Şekil 1'de gösterilen deney geometrisinde $100 \mathrm{mCi}$ 'lik ${ }^{241} \mathrm{Am}$ radyoaktif halka kaynağından çıkan $59,543 \mathrm{keV}$ 'lik fotonlar ile bütün numuneler 2000 sn bombardımana tabi tutuldu. Şekil 2'deki gibi demir pikleri elde edildi.

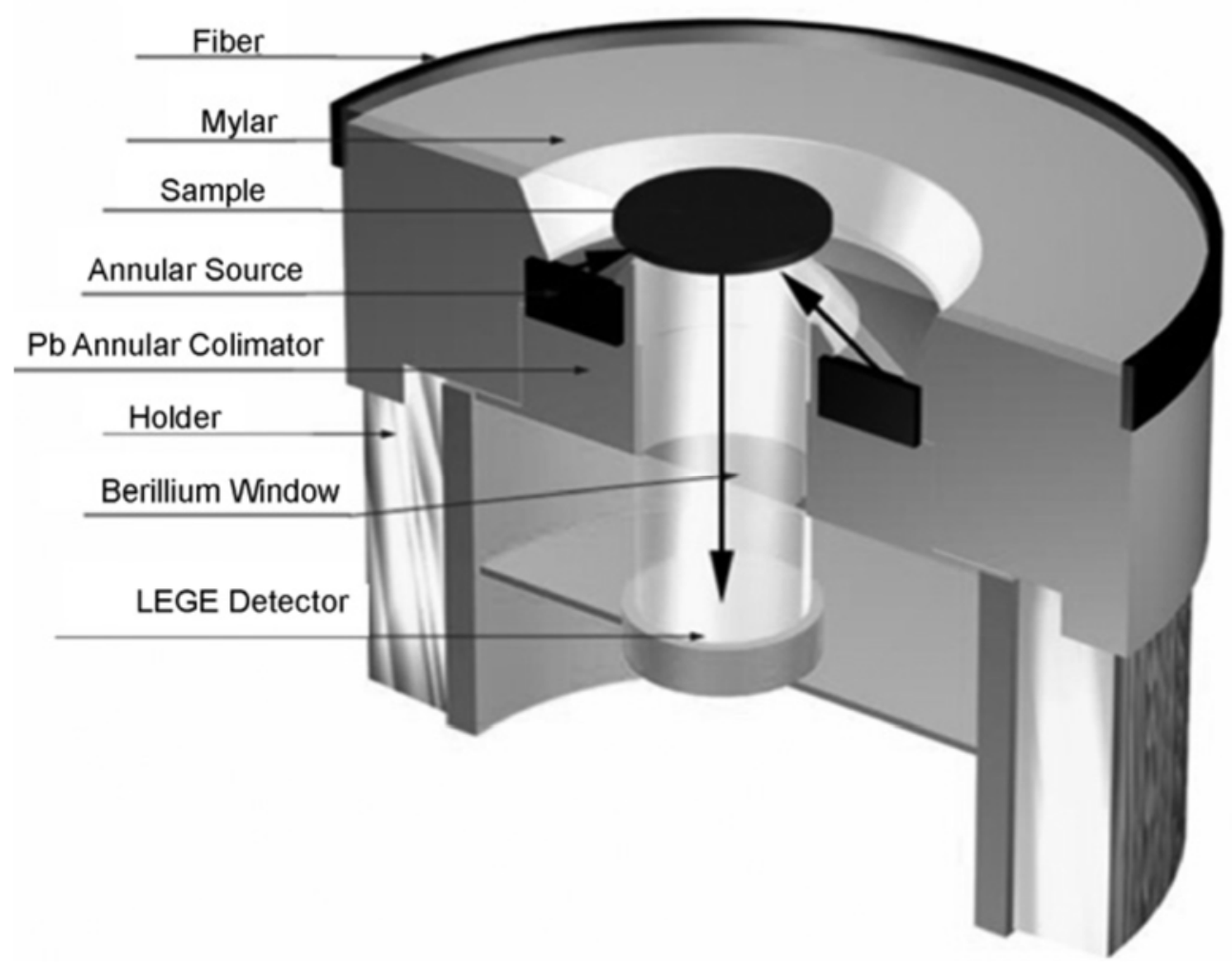

Şekil 1. Deney düzeneğinin geometrisi. 


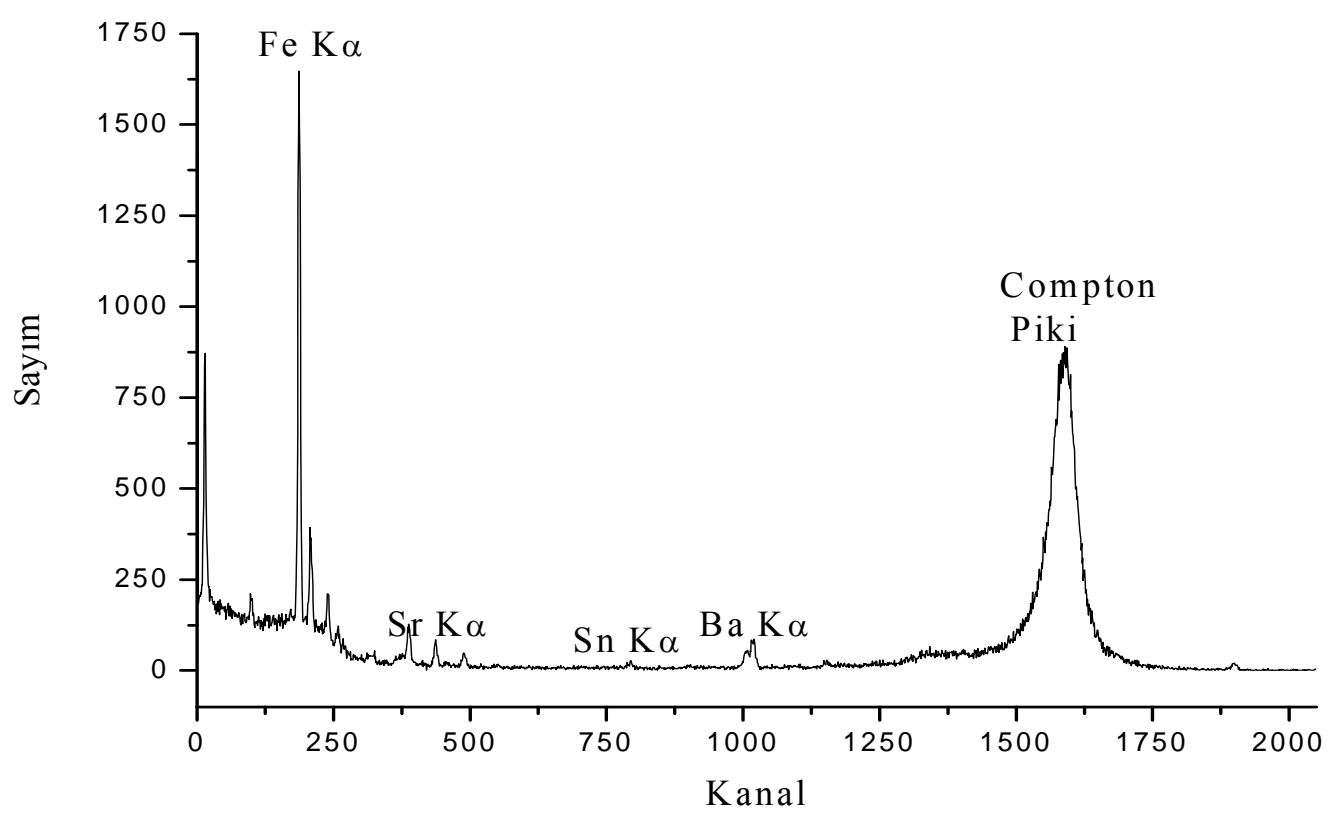

Şekil 2. ${ }^{241}$ Am Radyoaktif kaynağı tarafından uyarılmış numunenin tipik bir K-X 1şını spektrumu.

EDXRF'deki ölçümlerimizde sayma sistemimizden kaynaklanan hatalar \%0,5-5 arasındadır. Numune tartımından kaynaklanan hatalar, kaynak şiddeti ve sistem geometrisinden kaynaklanan hatalar \%4'tür. Bizim sonuçlarımızdaki toplam hata yaklaşık \%8 civarındadır.

\section{SONUÇLAR VE TARTIŞMA}

Tablo 1'de karayosunu numunelerinin, bahsedilen grupların her biri için demir absorpsiyon sonuçları verilmiştir. Buna göre; Thuidium tamariscinum'da 12.36 kat artış olurken, Homalothecium sericeum'da 13.95 kat, Eurhynchium striatulum'da 14.07 kat, Pleurozium schreberi'de 17.75 kat, Hypnum cupressiforme'de 19.92 kat, Eurhynchium striatum'da 31.2 kat artış olmuştur. Tablodan da görüldüğü gibi, karayosunlarının absorpsiyon kapasitesi şu şekildedir; Eurhynchium striatum > Hypnum cupressiforme > Pleurozium schreberi > Eurhynchium striatulum $>$ Thuidium tamariscinum $>$ Homalothecium sericeum. Böyle bir çalışma, karayosunlarının Fe absorpsiyonunun doğasını anlamak için gereklidir. 
Tablo 1. Karayosunu örneklerinin Fe absorpsiyon kapasitesi sonuçları.

\begin{tabular}{|l|l|l|l|l|l|l|l|}
\hline Örnek Ad1 & $\begin{array}{l}0 \% \mathrm{Fe} \\
(\mathrm{mg} / \mathrm{g})\end{array}$ & $\begin{array}{l}0.005 \% \\
\mathrm{Fe} \\
(\mathrm{mg} / \mathrm{g})\end{array}$ & $\begin{array}{l}0.05 \% \mathrm{Fe} \\
(\mathrm{mg} / \mathrm{g})\end{array}$ & $\begin{array}{l}0.5 \% \mathrm{Fe} \\
(\mathrm{mg} / \mathrm{g})\end{array}$ & $\begin{array}{l}\text { Artış } \\
\text { Oran1 }\end{array}$ & $\begin{array}{l}\text { Yaprak } \\
\text { uzunluğu } \\
\text { (Yaprağın } \\
\text { en uzun } \\
\text { kımı) } \\
(\mathrm{mm}), \\
(\text { Smith, } \\
2004)\end{array}$ & $\begin{array}{l}\text { Yaprak } \\
\text { genişliği(Y } \\
\text { aprağin en } \\
\text { geniş kımı } \\
\text { (mm), } \\
\text { (Smith, } \\
2004)\end{array}$ \\
\hline $\begin{array}{l}\text { Thuidium } \\
\text { tamariscinum }\end{array}$ & $11 \pm 0.88$ & $34 \pm 2.72$ & $64 \pm 5.2$ & $136 \pm 10.88$ & 12.36 & 1.4 & 1.15 \\
\hline $\begin{array}{l}\text { Homalothecium } \\
\text { sericeum }\end{array}$ & $24 \pm 1.92$ & $61 \pm 4.88$ & $136 \pm 10.88$ & $335 \pm 26.8$ & 13.95 & 4 & 1.32 \\
\hline $\begin{array}{l}\text { Eurhynchium } \\
\text { striatulum }\end{array}$ & $14 \pm 1.12$ & $37 \pm 2.96$ & $78 \pm 6.24$ & $197 \pm 15.76$ & 14.07 & 1.87 & 0.97 \\
\hline $\begin{array}{l}\text { Pleurozium } \\
\text { schreberi }\end{array}$ & $12 \pm 0.96$ & $38 \pm 3.04$ & $84 \pm 6.72$ & $213 \pm 17.04$ & 17.75 & 2.6 & 1.4 \\
\hline $\begin{array}{l}\text { Hypnum } \\
\text { cupressiforme }\end{array}$ & $28 \pm 2.24$ & $58 \pm 4.64$ & $227 \pm 18.16$ & $558 \pm 44.6$ & 19.92 & 2 & 0.93 \\
\hline $\begin{array}{l}\text { Eurhynchium } \\
\text { striatum }\end{array}$ & $15 \pm 1.2$ & $46 \pm 3.68$ & $134 \pm 10.72$ & $468 \pm 37.4$ & 31.2 & 3.25 & 2.1 \\
\hline
\end{tabular}

Bizim deneylerimizde, karayosunu türleri içinde en yüksek absorpsiyon kapasitesi Eurhynchium striatum'da, en düşük absorpsiyon kapasitesi ise Thuidium tamariscinum'da belirlenmiştir. Konsantrasyon değişimlerindeki en önemli faktörlerden birisi, karayosunu türlerinin yaprak yüzeylerinin ölçüsüdür. Tablo 1'e göre; deneyde kullanılan altı tür içinde, en geniş yaprak yüzeyine Eurhynchium striatum sahipken, en dar yaprak yüzeyine Hypnum cupressiforme sahiptir. Diğer taraftan bu altı tür içinde, en uzun yaprağa Homalothecium sericeum sahipken, en kısa yaprağa Thuidium tamariscinum sahiptir (Smith, 2004).

Tablo 2'de 2008 yılında bizim ilk yaptığımız çalışma ile şimdiki sonuçların kıyaslaması verilmiştir. $\mathrm{Bu}$ sonuçlara dayanarak, Sarp-Samsun sahil karayolu boyunca karayosunlarındaki muhtemel değişimleri belirledik ve altı karayosununun muhtemel durumlarını tabloda özetledik. Tablo 2'de, bu çalışmada kullanılan bütün türler, eğer Eurhynchium striatum olsaydı her bir bölgedeki yeni konsantrasyon değerleri hesaplandı. Eğer Hypnum cupressiforme yerine Eurhynchium striatum olsayd1, absorpsiyon kapasitesindeki farklıklıktan dolayı Hypnum cupressiforme'nin konsantrasyon değeri 1.56 kat artmış olacaktı. Eğer Pleurozium schreberi yerine Eurhynchium striatum olsaydı, Pleurozium schreberi'nin konsantrasyon değeri 1.75 kat artmış olacaktı. Benzer şekilde, eğer Homalothecium sericeum yerine Eurhynchium striatum olsaydı, Homalothecium sericeum'un konsantrasyon değeri 2.21 kat artmış olacaktı. Aynı şekilde Thuidium tamariscinum 2.23 kat ve Eurhynchium striatum'da 2.52 kat artmış olacaktı. Bu çalışmanın sonucu olarak, Tablo 2'deki sonuçlar bu şekilde değişecekti. 
Tablo 2. Sarp-Samsun karayolundaki karayosunlarındaki Fe düzeylerindeki değişiklikler Tablo 1'de verilen adsorpsiyon kapasitelerine göre aşağıdaki şekilde değişim gösterir.

\begin{tabular}{|c|c|c|c|c|c|}
\hline Karayosunu türleri & $\begin{array}{c}\mathrm{Fe} \\
(\mathrm{mg} / \mathrm{g})\end{array}$ & $\begin{array}{c}\text { Eğer bütün } \\
\text { örnekler } \\
\text { Eurhynchium } \\
\text { striatum olsaydı } \\
(\mathrm{mg} / \mathrm{g})\end{array}$ & $\begin{array}{c}\text { Muhteme } \\
1 \text { artışla } \\
\text { yeni } \\
\text { değer } \\
(\mathrm{mg} / \mathrm{g})\end{array}$ & $\begin{array}{c}\text { Eğer bütün } \\
\text { örnekler } \\
\text { Thuidium } \\
\text { tamariscinum } \\
\text { olsaydı (mg/g) }\end{array}$ & $\begin{array}{r}\text { Muhtem } \\
\text { azalışl } \\
\text { yeni des } \\
\quad(\mathrm{mg} / \mathrm{g}\end{array}$ \\
\hline Calliergonella cuspidata & $33.5 \pm 2.68$ & & & & \\
\hline Brachythecium albicans & $26.0 \pm 2.08$ & & & & \\
\hline Plagiothecium succulentum & $28.0 \pm 2.24$ & & & & \\
\hline Homalothecium sericeum & $38.9 \pm 3.1$ & 2.23 kat artış & 86.74 & 0,88 kat azalış & 34.23 \\
\hline Hypnum cupressiforme & $34.3 \pm 2.74$ & 1.56 kat artış & 53.5 & 0,62 kat azalış & 21.26 \\
\hline Pleurozium schreberi. & $35.3 \pm 2.82$ & 1.75 kat artış & 49.77 & 0,69 kat azalış & 24.35 \\
\hline Pleurozium schreberi & $47.6 \pm 3.8$ & 1.75 kat artış & 83.3 & 0,69 kat azalış & 32.84 \\
\hline Scleropodium purum & $29.7 \pm 2.36$ & & & & \\
\hline Homalothecium sericeum & $43.2 \pm 3.44$ & 2.23 kat artış & 96.33 & 0,88 kat azalış & 38.01 \\
\hline Eurhyncnium striatum & $55.3 \pm 4.42$ & & & 0,39 kat azalış & 21.56 \\
\hline Leptodictyum riparium & $104 \pm 8.2$ & & & & \\
\hline Eurhyncnium hians & $24.5 \pm 1.96$ & & & & \\
\hline Homalothecium sericeum & $13.1 \pm 1.04$ & 2,23 kat artış & 29.21 & 0,88 kat azalış & 11.52 \\
\hline Eurhyncnium striatum & $41.8 \pm 3.34$ & & & 0,39 kat azalış & 16.3 \\
\hline Hypnum cupressiforme & $42.5 \pm 3.4$ & 1.56 kat artış & 70.51 & 0,62 kat azalış & 26.35 \\
\hline Eurhyncnium striatum & $26.5 \pm 2.12$ & & & 0,39 kat azalış & 10.33 \\
\hline Homalothecium sericeum & $44.2 \pm 3.52$ & 2.23 kat artış & 98.56 & 0,88 kat azalış & 38.89 \\
\hline Hypnum resupinatum & $10.1 \pm 0.8$ & & & & \\
\hline Homalothecium sericeum & $34.6 \pm 2.76$ & 2.23 kat artış & 77.15 & 0,88 kat azalış & 30.44 \\
\hline
\end{tabular}

Amblystegium varium

Calliergonella cuspidata

Tortella fragilis

Homalothecium sericeum

Eurhyncnium striatum

Homalothecium sericeum

Hypnum cupressiforme

Pleurozium schreberi
$7.8 \pm 0.62$

$39.2 \pm 3.36$

$42.2 \pm 3.36$

$37.1 \pm 2.96$

2.23 kat artış

$45.1 \pm 3.6$

$36.6 \pm 2.92$

2.23 kat artış

$38.4 \pm 3.06$

1.56 kat artış

$25.2 \pm 2.0$
$82.73 \quad 0,88$ kat azalıs

32.64

0,39 kat azalış

17.58

$81.61 \quad 0,88$ kat azalış

32.2

$59.9 \quad 0,62$ kat azalış

23.8

$44.1 \quad 0,69$ kat azalış 


\begin{tabular}{|c|c|c|c|c|c|}
\hline Eurhyncnium striatum & $72.4 \pm 5.6$ & & & 0,39 kat azalış & 28.23 \\
\hline Hypnum cupressiforme & $41.6 \pm 3.2$ & 1.56 kat artış & 64.89 & 0,62 kat azalış & 25.79 \\
\hline Eurhyncnium striatum & $49 \pm 3.92$ & & & 0,39 kat azalış & 19.11 \\
\hline Hypnum cupressiforme & $59.9 \pm 4.8$ & 1.56 kat artış & 93.44 & 0,62 kat azalış & 37.13 \\
\hline Homalothecium sericeum & $41.5 \pm 3.2$ & 2.23 kat artış & 92.54 & 0,88 kat azalış & 36.52 \\
\hline Homalothecium sericeum & $72.8 \pm 5.8$ & 2.23 kat artış & 162.34 & 0,88 kat azalış & \\
\hline Brachythecium albicans & $35.1 \pm 2.8$ & & & & \\
\hline Ctenidium molluscum & $65 \pm 5.2$ & & & & \\
\hline Calliergonella cuspidata & $23.2 \pm 1.84$ & & & & \\
\hline Hypnum cupressiforme & $6.1 \pm 0.48$ & 1.56 kat artış & 9.51 & 0,62 kat azalış & 3.78 \\
\hline Rhynchostegium murale & $24.9 \pm 1.98$ & & & & \\
\hline Bryum capillare & $8.3 \pm 6.64$ & & & & \\
\hline Eurhynchium striatum & $15.6 \pm 1.24$ & & & 0,39 kat azalış & 6.08 \\
\hline Amblystegium varium & $7.7 \pm 0.6$ & & & & \\
\hline Hypnum resupinatum & $28.9 \pm 2.3$ & & & & \\
\hline Brachythecium albicans & $46.6 \pm 3.72$ & & & & \\
\hline Eurhynchium striatum & $25.9 \pm 2.06$ & & & 0,39 kat azalış & 10.1 \\
\hline Hypnum cupressiforme & $45.8 \pm 3.66$ & 1.56 kat artış & 71.44 & 0,62 kat azalış & 28.39 \\
\hline Rhytidiadelphus squarrosus & $47.1 \pm 3.76$ & & & & \\
\hline Hypnum cupressiforme & $37 \pm 2.96$ & 1.56 kat artış & 57.72 & 0,62 kat azalış & 22.94 \\
\hline Hypnum cupressiforme & $35.9 \pm 2.86$ & 1.56 kat artış & 56.0 & 0,62 kat azalış & 22.25 \\
\hline Thuidium tamariscinum & $29 \pm 2.32$ & 2.52 kat artış & 73.08 & & \\
\hline Amblystegium varium & $44.4 \pm 3.44$ & & & & \\
\hline Homalothecium sericeum & $38.4 \pm 3.06$ & 2.23 kat artış & 85.63 & 0,88 kat azalış & 33.79 \\
\hline Eurhynchium striatum & $47.9 \pm 3.82$ & & & 0,39 kat azalış & 18.68 \\
\hline Scleropodium purum & $35.8 \pm 2.86$ & & & & \\
\hline Plagiothecium succulentum & $47.5 \pm 3.8$ & & & & \\
\hline Leucodon sciuroides & $47.5 \pm 3.8$ & & & & \\
\hline Scleropodium purum & $53.8 \pm 4.3$ & & & & \\
\hline Scleropodium purum & $42.0 \pm 3.36$ & & & & \\
\hline Homalothecium sericeum & $49.7 \pm 3.96$ & 2.23 kat artış & 110.83 & 0,88 kat azalış & 43.73 \\
\hline Ctenidium molluscum & $51.6 \pm 4.12$ & & & & \\
\hline Hypnum cupressiforme & $52.6 \pm 4.2$ & 1.56 kat artış & 82.05 & 0,62 kat azalış & 32.61 \\
\hline Eurhynchium striatulum & $23.2 \pm 1.84$ & $2.21 \mathrm{~kat}$ artış & 51.27 & 0,87 kat azalış & 20.18 \\
\hline Ctenidium molluscum & $39.5 \pm 3.16$ & & & & \\
\hline Brachythecium mildeanum & $50.3 \pm 4.02$ & & & & \\
\hline
\end{tabular}


Ctenidium molluscum

Ctenidium molluscum

Homalothecium sericeum

Leucodon sciuroides

Brachythecium albicans

Brachythecium mildeanum

Pleurozium schreberi

Amblystegium varium

Eurhynchium striatum

Hypnum cupressiforme

Tortella fragilis
$40.2 \pm 3.2$

$40.8 \pm 3.26$

$49.8 \pm 3.98$

2.23 kat artış

11.05

0,88 kat azalış

43.82

$42.8 \pm 3.4$

$46.1 \pm 3.68$

$62.8 \pm 5.02$

$42.4 \pm 3.38$

1.75 kat artış

74.2

0,69 kat azalış

29.25

$6.9 \pm 0.54$

$53.2 \pm 4.2$

$47.3 \pm 3.78$

1.56 kat artış

73.78

0,39 kat azalış

20.74

$53.3 \pm 4.26$

Yukarıdaki durumun tersi olarak, bu altı tür içinde en düşük Fe absorpsiyon kapasitesinin Thuidium tamariscinum olduğu belirlendi. Eğer Eurhynchium striatum yerine Thuidium tamariscinum olsayd1, Eurhynchium striatum'un konsantrasyon değeri 0.39 kat azalmış olacaktı. Aynı şekilde, Hypnum cupressiforme, Pleurozium schreberi, Eurhynchium striatulum ve Homalothecium sericeum'da 0.62, 0.69, 0.87 ve 0.88 kat azalmış olacaktı. Tablo 2'de bütün bu değişim oranları verilmiştir.

Maher ve ark., (2008) ve Rauch ve ark., (2001) bizim çalışmamıza paralel olarak yaptıkları çalışmalarda, trafik aktivitesinin yoğun olduğu yerlerde havadaki partiküllerin sayısı ile trafik yoğunluğu arasındaki ilişkiyi göstererek bizim çalışmamızı onayladılar. Havadaki partiküllerin yakalanmasındaki farklılıkların, yaprak yüzeyinin yapısındaki farklılıklar ile ilişkisi vardır (FreerSmith ve ark., 2004, Kardel ve ark., 2012, Mitchell ve ark., 2010, Weijers ve ark., 2004).

Çevik ve ark., (2010), Türkiye'nin İskenderun körfezindeki demir analizleri için karayosunlarını kullanmışlardır. Zechmeister ve ark., (2005), araç trafiğinden kaynaklanan demir seviyesini belirlemek için karayosunlarını kullanmışlardır. Araç trafiği ile demir konsantrasyonu arasında güçlü bir ilişki vardır, karayolundan uzaklaştıkça demir konsantrasyonunda da azalma görülmüştür (Zechmeister ve ark., 2005).

Bryofitlerden sadece birkaç tür endüstriyel kirliliğe tolerans gösterebilmesine rağmen, genelde bryofitler kirliliğe duyarlı bitkilerdir yani indikator bitkilerdir ve kirli olan bölgelerde genelde az bulunurlar. Epifitik bryofitler özellikle hava kirliliğine karşı duyarlıdırlar. Bryofitler ağır metallerin pasif toplayıcısıdırlar. Karayosunları, ağır metalleri, tohumlu bitkilerden yaklaşık iki kat daha fazla depolayabilirler. Bunun sebebi; Dokularının kuru ağırlığının yüzey alanlarına oranı ile ilişkilidir. Bryofitlerin kimyasal analizleri, bir ekosistemdeki ağır metal konsantrasyonlarını hızlı ve masrafsız bir şekilde incelemek için en uygun yöntemlerden birisidir. (Schofield, 2001). 
Sonuç olarak; Altı karayosunu türünün demir absorplama yetenekleri çalışılmıştır ve bunun sonucunda yaprak yüzey alanları ile absorplama yetenekleri arasında ilişki olduğu ortaya konulmuştur. $\mathrm{Bu}$ sıralama en çok absorplama yeteneği olandan az olana doğru şu şekilde sıralanmaktadır; Eurhynchium striatum, Hypnum cupressiforme, Pleurozium schreberi, Eurhynchium striatulum, Thuidium tamariscinum ve Homalothecium sericeum. Deneysel sonuçlar gösterdi ki; Karayosunlarının yaprak yüzey alanları ile demir absorplama yetenekleri arasında pozitif bir ilişki vardır. Ayrıca; bu çalışma ile, karayosunlarının ağır metal analizleri çalışmalarında iyi bir indikatör bitki oldukları da tekrar görülmüş oldu. Dünya da 23000 türü bulunan karayosunlarının, biz sadece altı türünde böyle bir çalışma yaptık, bundan sonra diğer türlerde de böyle çalışmalar yapılması ve demir'den başka ağır metaller için de benzer çalışmalar uygulanmasında çevre kirliliğinin belirlenmesi açısından fayda vardır.

\section{Kaynaklar}

Cevik, U., Koz, B., Makarovska, Y. (2010). Heavy Metal Analysis in Iskenderun Bay in Turkey. X-Ray Spectrometry, 39, 3, 202-207.

Frey, W., Fram, J.P., Fischer, E., Lobin,W. (1995). Die Moos-und Farnpflanzen Europas, Stuttgart, Germany.

Freer-Smith, P.H., El-Khatib, A.A., Taylor, G. (2004). Capture of particulate pollution by trees: a comparison of species typical of semi-arid areas (Ficus nitida and Eucalyptus globulus) within European and North American species. Water Air \& Soil Pollution, 155, 173-187.

Grodzinska, K., Szarek-Lukaszewska, G. (2001). Response of mosses to the heavy metal deposition in Poland-an overwiev. Environmental Pollution, 114, 443-451.

Harrison, R.M., Smith, D.J.T., Luhana, L. (1996). Source apportionment of polycyclic aromatic hydrocarbons collected from an urban location in Birmingham, UK. Environmental Science and Technology, 30, 825-832.

Kardel, F., Wuyts, K., Maher, B.A., Samson, R. (2012). Intra-Urban spatial variation of magnetic particles: Monitoring via leaf saturation isothermal remanent magnetization(SIRM). Atmospheric Environment, 55, 111-120.

Koz, B., Cevik, U., Ozdemir, T., Duran, C., Kaya, S., Gundogdu, A., Celik, N. (2008). Analysis of mosses along Sarp-Samsun highway in Turkey. Journal of Hazardous Materials, 153, 646-654.

Kristensson, A., Johansson, C., Westerholm, R., Swietlicki, E., Gidhagen, L.,Widequist, U., Vesely, V. (2004). Real-world traffic emission factors of gases and particles measured in a road tunnel in Stockholm, Sweden. Atmospheric Environment, 38(7), 657-673,

Lee, C.S.L., Li, X., Zhang, G., Peng, X., Li, Z. (2005). Biomonitoring of trace metals in the atmosphere using moss (Hypnum plumaeforme) in the Nanling Mountains and the Pearl River Delta, Southern China. Atmospheric Environment, 39, 397-407.

Maher, B.A., Moore, C., Matzka, J. (2008). Spatial variation in vehicle-derived metal pollution identified by magnetic and elemental analysis of roadside tree leaves. Atmospheric Environment, 42, 364-373.

Mitchell, R., Maher, B.A., Kinnersley, R. (2010). Rates of particulate pollution deposition onto leaf surfaces: temporal and inter-species magnetic analyses. Environmental Pollution, 158, 1472-1478.

Pedrotti, C.C. (2001). Flora Dei Muschi D'Italia, Roma, Italia.

Rauch, S., Lu, M., Morrison, G.M. (2001). Heterogenity of platinum group metals in airborne particles. Environmental Science and Technology, 35, 595-599.

Schofield, W.B. (2001). Introduction to Bryology. The Blackburn Press, Cardwell, New Jersey: U.S.A., pp. 263-267.

Smith, A.J.E. (2004). The Moss Flora of Britain and Ireland. Cambridge University Press, Cambridge, U.K., pp. 748, 816, 846, 849, 902, 924. 
Uyar, G., Ören, M., İnce, M. (2007). Atmospheric Heavy Metal Deposition in Düzce Province by Using Mosses as Biomonitors. Fresenius Environmental Bulletin, 16, 145-153.

Weijers, E.P., Khlystov, A.Y., Kos, G.P.A., Erisman, J.W. (2004). Variability of particulate matter concentrations along roads and motorways determined by a moving measurement unit. Atmospheric Environment, 38, 2993-3002.

Wolterbeek, B. (2002). Biomonitoring of trace element air pollution: principles, possibilities and perspectives. Environmental Pollution, 120(1), 11-21.

Zechmeister, H.G., Hohenwallner, D., Riss, A., Hanus-Illnar, A. (2005). Estimation of element deposition derived from road sources by using mosses. Environmental Pollution, 138, 238-249. 